\title{
Nachruf auf die Breslauer Professorin Anna Stroka (15. April 1923-10. Juli 2020)
}

Am 10. Juli 2020 ist Anna Stroka, emeritierte Germanistikprofessorin an der Universität Wrocław, im Alter von 97 Jahren verstorben. Während ihrer gesamten universitären Laufbahn war sie eng mit der Alma Mater Wratislaviensis verbunden, an der sie alle Sprossen der akademischen Karriereleiter erklommen hat: von der Studentin bis zur Professorin.

Einige Stationen ihres wissenschaftlichen Werdegangs seien an dieser Stelle in aller Kürze zusammengefasst: Im Jahr 1948 nahm Anna Stroka das Germanistikstudium auf und noch vor dessen Abschluss trat sie eine unbesoldete Assistentenstelle an. Nach dem Magisterexamen promovierte sie 1961 mit ihrer Dissertation über das Thema Carl Hauptmanns Werdegang als Denker und Dichter. 1974 habilitierte sie mit ihrer Monographie über Arthur Schnitzler und sein dramatisches Werk. 1991 wurde Anna Stroka außerordentliche Professorin an der Universität Wrocław; die Krönung ihres beruflichen Weges fällt in das Jahr 1992, als ihr der Präsident der Republik Polen eine ordentliche Professur verlieh.

Das Engagement und der hohe persönliche Einsatz - als Prodekanin der Philologischen Fakultät, als stellvertretende Direktorin des Instituts für Germanistik oder als Leiterin des Doktorandenstudiums - mit dem Anna Stroka immer wieder neue akademische Aufgaben angenommen und bewältigt hat, sind beeindruckend. Die vormalige Mitarbeiterin des 1992 verstorbenen Prof. Dr. Marian Szyrocki wurde zu dessen Nachfolgerin auf den Lehrstuhl für Deutsche, Österreichische und Schweizerische Literatur und Kultur des 19. und 20. Jahrhunderts berufen, den sie bis zu ihrer Emeritierung souverän leitete.

Prof. Dr. Anna Stroka spezialisierte sich auf mehreren Gebieten der germanistischen Literatur- und Kulturwissenschaft. Ihre Hauptforschungen widmete sie der deutschsprachigen Literatur des 19. und 20. Jahrhunderts, mit besonderer Berücksichtigung der österreichischen Literatur, wobei der Schwerpunkt auf dem literarischen Werk Arthur Schnitzlers lag. Des Weiteren konzentrierte sie sich im Rahmen der Schlesienforschung u.a. auf das literarische Werk Carl und Gerhart Hauptmanns.

Hier soll nicht versucht werden, die inhaltlichen Facetten ihres breiten thematischen Spektrums vollständig aufzuzählen. Schon ein kurzer Blick in ihre Forschungsbibliographie, die Monographien, Editionen, Aufsätze, Lexikonbeiträ- 
ge und Rezensionen umfasst, verdeutlicht die enorme Dimension ihres Lebenswerkes. Hervorzuheben sind auch die von ihr mit herausgegebenen Lehrwerke zur Geschichte der deutschsprachigen Literatur und ihre großartigen Übersetzungen von Texten zur schlesischen, meist Breslauer, Kulturgeschichte. In Anerkennung ihrer Leistungen wurde Prof. Dr. Anna Stroka mit mehreren Auszeichnungen gewürdigt.

Als gefragte Expertin war sie Mitglied in akademischen Organisationen und Redaktionskollegien und nahm als Referentin unermüdlich an polnischen wie internationalen Kongressen, Tagungen und Seminaren teil. Ihre Gastvorträge fanden in Polen ebenso wie im deutschsprachigen Ausland eine durchgehend positive Resonanz: Anna Stroka genoss in der internationalen Germanistik hohes Ansehen.

Einen Großteil ihres ungewöhnlich aktiven Lebens widmete sie der Didaktik. Sie war Hochschullehrerin aus tiefer Überzeugung, immer den Studierenden zugewandt. Durch ihre herzliche Offenheit und ihre Hilfsbereitschaft motivierte sie Studentinnen und Studenten zur Diskussion und teilte dabei ihr umfangreiches Wissen mit ihnen. Das Lehrangebot von Frau Prof. Stroka erfreute sich großer Beliebtheit, ihre Seminare waren ausnahmslos stark frequentiert. Dieses vorbildliche Engagement für die Ausbildung der Studierenden und des wissenschaftlichen Nachwuchses allgemein verdient ganz besonderen Respekt: Es sind Hunderte von Magisterarbeiten und etliche Dissertationen und Habilitationen, die sie als wissenschaftliche Betreuerin, Mentorin oder Gutachterin begleitet und unterstützt hat. Mehrere Generationen polnischer Germanisten, darunter zahlreiche Mitarbeiter des Germanistischen Instituts an der Universität Wrocław, sind ihrer Lehrerin für diese herausragende, oft ganz individuell gestaltete Förderung dankend verbunden.

Heute kann man nur mit Bewunderung auf die Tätigkeit Anna Strokas zurückblicken: Sie hat einen nicht zu unterschätzenden Beitrag dazu geleistet, dass die Wende des Jahres 1989 für die Breslauer Germanistik im Hinblick auf ihr programmatisches Profil keine Zäsur bildete. Denn schon lange zuvor, mitten in den schwierigen Zeiten der kommunistischen Unfreiheit und Indoktrination, öffnete sie das Fenster zur Welt. Sie ermöglichte den jungen Menschen Studien- und Forschungsaufenthalte in Österreich und in der Bundesrepublik Deutschland, wie auch Kontakte mit Wissenschaftlern und Schriftstellern aus dem Westen. Als selbstbewusste Oberschlesierin vermittelte sie einen ganz undoktrinären Umgang mit der schlesischen Kulturgeschichte und ein vielfältiges, multiperspektivisches Schlesienbild, das von dem damaligen propagandistisch vergifteten Korsett vollkommen frei war. Frau Stroka war mit ihrem gelebten, auf christlichen und universellen Werten beruhenden ethischen Kodex für uns eine wegwesende Autorität und zugleich eine absolut integre Persönlichkeit!

Die Emeritierung bedeutete für Anna Stroka die Fortsetzung ihrer akademischen Tätigkeit, denn sie war als Professorin noch jahrelang an der Breslauer Philologischen Hochschule erfolgreich tätig. Davon zeugen ihre letzten Publikationen, die mit intensiven Recherchen in den wissenschaftlichen Bibliotheken Breslaus 
einhergingen, gerade auch in unserer germanistischen Institutsbibliothek, die ihr Herzensanliegen war. Prof. Stroka interessierte sich bis an ihr Lebensende für die Weiterentwicklung der Breslauer Germanistik. In zahlreichen Gesprächen fanden wir in ihr stets eine hochkompetente und inspirierende Ratgeberin.

Mit tief empfundener Dankbarkeit denken wir an die großartige wissenschaftliche Persönlichkeit Anna Strokas und an ihre liebenswürdige Humanität zurück. Wir verneigen uns vor der unvergesslichen Nestorin der Breslauer Germanistik.

Marek Hałub 